\title{
ASPECTUAL SHIFT AS TYPE COERCION ${ }^{1}$
}

\author{
Stephen G. Pulman \\ SRI International Cambridge Computer Science Research Centre \\ and \\ University of Cambridge Computer Laboratory
}

\begin{abstract}
The phenomenon of aspectual shift has been discussed by several people over the last ten years using an analogy with type coercion in programming languages. This paper tries to take the analogy literally and to spell out the details for an analysis of some common kinds of aspectual shift in English under the influence of some types of temporal modification. A model theoretic basis for this kind of type coercion is supplied, and an illustrative fragment is worked out.
\end{abstract}

\section{Introduction}

Determination of aspectual status of a sentence or phrase means working out whether it describes an event or a state, and what semantically relevant internal structure the event or state might have. While inherent lexical or structural semantic properties place constraints on the possibilities for aspectual status, they do not uniquely determine it, and it is not an objective property of the situations that sentences describe that one or other aspectual status is the only correct one (see, for example, Bach 1981). The aspectual status of a sentence presents a particular way of looking at an episode or situation, or a component of an episode or situation, such that contextual assumptions about its temporal, causal, or relevance relations to other events are required for felicitous interpretation. These assumptions, if they are not explicit in the context, may be conveyed as additional implicated or presupposed information, if the hearer knows that they are required to motivate a particular aspectual choice on the part of the speaker.

However, although aspectual status is not an objective semantic property of the situations sentences describe (in the way, for example, that any situation standardly describable as 'kissing' will also be standardly describable as 'touching', legitimating the entailment from 'kiss' to 'touch'), we often need to determine aspectual status in order to know about the truth conditions or the entailments

\footnotetext{
${ }^{1}$ Published as: S. G. Pulman, 1997, Aspectual Shift as Type Coercion, in Transactions of the Philological Society, 95:2, 279-317.
} 
of a sentence. A sentence which describes a state is typically (though not invariably) intended to be evaluated at the current temporal reference point. Thus both sentences in a discourse like 1 a will be evaluated at the same temporal reference point. A sentence describing an event will typically (though not invariably) advance the current temporal reference point. The sentences in $1 \mathrm{~b}$ will therefore typically be taken to describe immediately succeeding events (see e.g. Kamp and Reyle 1993:510).

1 a The printer jammed. The paper was too thick.

b The printer jammed. The warning light came on.

Aspectual status may also determine whether we can have singular or plural event reference:

2 a The princess protested as the photographer interrupted.

Her protest was ignored

b The princess protested throughout her trip.

Her protests were ignored

If there is an iterative or repetitive interpretation, as in (b), it is implied that more than one protest occurred.

In some languages, this particular aspectual difference is formally marked by a 'repetitive' aspect auxiliary or morpheme of some kind. For example, in Turkish, the first sentence of the (a) and (b) examples would be most naturally translated as:

3 a Prenses, fotoğrafčı araya girince protesto etti. Princess, photographer when interrupted protested.

b Prenses yolculuk boyunca protesto etti durdu. Princess, trip during protested stopped (literally)

The 'durdu' imposes a repetitive interpretation.

We need to determine the internal aspectual structure of sentences like:

4 a Joe was building his house there for a year

b Joe pitched his tent there for a year

5 a Joe drove a car for a day

b Joe hired a car for a day

in order to know that, on their most salient interpretations, the (a) sentences entail that Joe was carrying out the activity described for a year or a day respectively, whereas the (b) sentences do not. Correspondingly, 4 (b) entails that the tent was standing there for the year whereas 4(a) does not entail that the house was. In 5, the (b) sentence says that the state resulting from hiring the car (namely, being in possession of it) held for a day, whereas there is no analogous claim about states in (a). 
Although particular verbs may, when taken in isolation, be more naturally interpreted in one way than another ('sneeze' describes events, 'like' describes states), phrases containing them may have different status when the verbs are combined with arguments or modifiers. We have already seen examples of the latter type of aspectual shift: shift when combined with modifiers is illustrated by:

6 a ?The soldier arrived all morning

b The soldiers arrived all morning

7 a ?Joe ate a cake for an hour

b Joe ate cake for an hour

Multiple shifts are also possible, as shown in Moens and Steedman's splendid example (1988:20):

8 It took me two weeks to play the Minute Waltz in less than sixty seconds for an hour

This phenomenon of aspectual shift or aspectual coercion has of course been widely discussed in the literature (e.g. Verkuyl 1972, 1993; Dowty 1979; Jackendoff 1991; Krifka 1987, 1991; Moens and Steedman 1988; Pustejovsky 1991; Smith 1991; Kamp and Reyle 1993; Pustejovsky and Bouillon 1996). However, it has proved remarkably difficult to systematise the mechanisms governing the phenomenon. Kamp and Reyle write:

'... the central problem for the theory of aspect is to determine how the aspectual characteristics of complex phrases are determined by those of their parts' (Kamp and Reyle 1993:570)

This quotation should not be taken to suggest that aspectual coercion is a fully compositional process, since there are also significant contextual constraints on plausible interpretations. In fact the determination of aspectual status (both as a linguistic and a computational problem) seems to fall in the middle ground between compositional, syntax-driven semantic assembly, and full-blown contextual reasoning. There are structural and lexical constraints on the linguistic possibilities that are made available, and the role of contextual reasoning is not (as it is for some kinds of referential phenomena) to supply candidate interpretations but rather to select between the linguistically available possibilities. (In this respect, aspectual composition has some of the properties of quantifier scope).

While several of the works cited above constitute notable attempts to describe detailed mechanisms for capturing particular kinds of aspectual determination, it has proved difficult to provide a comprehensive description of the phenomena in a way which achieves closure with other relevant aspects of semantic composition.

The aim of the present work is to systematise some basic aspectual phenomena within a formal framework that lends itself to practical computational implemen- 
tation within a variety of theoretical paradigms. The paper is thus to be seen as a sketch of a computational semantics 'module' of the type discussed in the FraCaS project deliverables, (Cooper at al. 1996: see also http://www.cogsci.ed.ac.uk/ ${ }^{\sim}$ fracas) somewhat analogous to, say, the Hobbs-Shieber (Hobbs and Shieber 1987) algorithm for quantifier scoping: i.e. it provides enough detail for an initial practical implementation without making strong presuppositions about the rest of the semantic framework it is part of.

The structure of the paper is as follows. Firstly, a brief review of some of the most influential recent approaches to aspectual determination within formal or computationally oriented linguistics is presented. From these I abstract a core which is intended to represent as nearly as possible a consensus view of the central phenomena. Next, a brisk illustration of the linguistic data covered by this core is given, exemplifying informally the various components needed by an aspectual determination mechanism. The work of Moens and Steedman is a major influence on the presentation here.

The underlying model theory to support aspectual shift as a species of type coercion is described. Finally, an illustrative syntactic and semantic fragment follows, which assigns meaning representations to sentences of various aspectual types. Some issues relevant for computational implementation are also discussed.

\section{Basic notions}

The locus classicus of recent work on English aspectual classification is Vendler (1967). He used various diagnostic criteria to distinguish between four classes of verb (although it should really be phrases and sentences that are so classified). The various tests are amply discussed in the literature (e.g. Dowty 1979:p55 ff; Verkuyl 1993: chapter 2) and will only be briefly summarised here.

States:

- typically cannot occur in the progressive, imperative, or in any construct imputing agency or voluntary control to the subject.

- typically can occur in simple present with present time reference, without generic or habitual interpretation

Activities:

- can be modified by 'for+time-period' without special context

- cannot be modified by 'in+time-period' without special context 
- ' $\mathrm{X}$ is (now) V-ing' entails ' $\mathrm{X}$ has V-ed'.

Accomplishments:

- cannot always be modified by 'for+time-period' without special context

- can be modified by 'in+time-period' without special context

- ' $\mathrm{X}$ is (now) V-ing' does not entail ' $\mathrm{X}$ has V-ed' (at least, not in the situation being described)

- 'X V-ed in Y time' entails ' $\mathrm{X}$ was Ving during Y time'.

Achievements:

- cannot usually be modified by 'for+time-period' without special context

- can be modified by 'in+time-period' without special context

- ' $\mathrm{X}$ V-ed in Y time' does not entail ' $\mathrm{X}$ was Ving during $\mathrm{Y}$ time'.

As the use of adverbs like 'typically' and 'usually' suggests, in particular cases, it is not always completely clear as to whether the tests apply at all, and when they do, it is not always clear as to whether they give a clear result. This is likely to be unavoidable in any area where conceptual differences are not clearly formally marked.

Most recent authors try to rationalise this aspectual taxonomy by relating it to an ontology which distinguishes between events, which suggest change, and states, which do not. Some also distinguish a separate category of processes (more or less equivalent to Vendler's activities) which may or may not suggest change. Processes are usually thought of as consuming resources in some way. The term 'eventuality' (Bach 1981:69) has been introduced to subsume all kinds of events and states. Eventualities can also be viewed as wholes, without distinguishing internal structure. If they are viewed as wholes, I will follow many authors (e.g. Moens and Steedman, 1988) in calling them 'points'.

Opinions differ on the nature of the internal structure of events themselves. Moens and Steedman, Kamp and Reyle (1993) and others regard an event as consisting of a triple:

<preparatory process, culmination point, consequent state>

Kamp and Reyle (p558) characterise 'accomplishment' verbs as those which, in the simple past, describe the preparatory process+culmination components, 
'achievement verbs' as those describing the culmination point alone, and 'activity' verbs as describing just the preparatory process (unless the culmination is supplied by an argument).

An alternative taxonomy is offered by Pustejovsky (1991) in which there are just events, states, and 'transitions' (tuples of events or states), which include achievements and accomplishments. The latter differ, according to Pustejovsky, only in that accomplishments involve agency and achievements do not (p 59). While the interaction between aspectual categories and agency is undoubtedly very complex, and while Pustejovsky's observation (see also Dowty 1979) is close to being true, it must still be the case that there is more to the distinction between these categories than the presence or absence of agency. It is hard to see how agency alone could account for the inferential differences in the following (from Kamp and Reyle, 1993: 560-561)

9 a Mary died at 10.15

* Mary was dying at 10.15

b Mary wrote the letter this morning

Mary was writing the letter this morning

Note that Verkuyl is an exception to this Vendler-derived tradition: he is somewhat skeptical about the value of such a categorisation in explaining aspectual phenomena (see, for example, 1993: 65, 267), and regards the basic opposition as being that between terminative and durational aspect. I suspect that this is largely due to the fact that he concentrates exclusively on aspectual changes accompanying the combination of a verb with different types of argument (1993:xii), and also to the fact that he appears to assume that everyone using some version of these categories endorses Vendler's mistaken belief that the classes are lexically determined. Once it is accepted that aspectual classes are (semi-) compositionally derived properties of phrases and sentences, the differences between Verkuyl's position and most of the others described here (at least, where they are describing the same phenomena) are much less striking than the similarities.

In what follows, I will adopt a taxonomy originally developed in Pulman 1977, which can be seen as a conservative blend of those of Vendler, Kamp and Reyle, Moens and Steedman, and Pustejovsky, although considerably predating all but the first.

The basic kinds of eventuality are states (state), points (point), and processes (process ). States are understood in the usual way, as things which persist over time. Where they are explicitly asserted to hold over some period of time, they are divisible: that is, they are understood to hold homogeneously over all relevant smaller periods within that time. States are cumulative in the sense that if a state holds over some period, and also over some immediately adjacent period, then the state holds over the combination of both periods. Typically it is not possible 
linguistically to refocus on any internal components of states: they do not have them. (This may not always be true of states that are the results of aspectual coercions).

Points are atomic events: any internal temporal or other structure they may in reality have is ignored by categorising them in this way. While some of Vendler's achievements would here be classified as points, there is no implication of any salient consequent state with points (as there often is for achievements). I follow Moens and Steedman, among others, in seeing the necessity for a separate category of points.

Processes are somewhat similar to states in that they typically are thought of as persisting over time, and they are cumulative. However, they are not homogenous in the same way as states, in two senses: firstly, processes are regarded as consuming input or proceeding via a series of implicit micro-events many of which could be singled out for an alternative linguistic characterisation if necessary. Secondly, especially where plurality, iteration, or other coercion factors are involved, there is a lower bound on the divisibility of processes.

In this taxonomy, Vendler's distinctions are largely preserved: states are identical, activities are renamed as processes, but an extra 'point' is introduced, and two of his categories are regarded as complex rather than primitive. These are <point, state> or <process, state> pairs, corresponding to achievements ('culminations' for Moens and Steedman) and accomplishments ('culminated processes') respectively. I therefore agree with Pustejovsky that it is useful to see these as complex entities, but differ from him in where the difference lies. Our taxonomy also differs from that of Kamp and Reyle in that both achievements and accomplishments are taken to include reference to a consequent state, and the difference between them is ascribed to the fact that the event resulting in this state is either a point or a process. The motivation for this treatment is that explicit reference to states is possible even without use of the perfect when the right kind of temporal adverb is present, as will be argued below.

It is implicit in this taxonomy that while it is conceptually possible to assign a tripartite structure to events, it is not necessary to do so for linguistic reasons. My original motivation for this was that while there are phenomena in which both separate components of the <point, state> and <process, state> combinations are modified separately, there are no clear examples where all three components of the more complex structure can be accessed independently and simultaneously. (Notice that Moens and Steedman's discussion $(\mathrm{p} 15,23)$ of the semantics of 'when', which largely motivates their view of events, still only requires a decomposition of events into preparatory process and consequent state.) Of course, if this proves to be wrong it is simple to move to a taxonomy based on the more complex structure. We return to this issue below. 
Moens and Steedman described shifts in aspectual status as a kind of coercion by a 'loose analogy' with type coercion in programming languages. A similar analogy is pursued by Pustejovsky. 'Type coercion' refers to the situation in programming languages when a function is given input of a type that it is not defined for, but is able to deal with it nonetheless. An example might be a function that expects a number, but which is passed a string "24.5" whose characters are the print representation of a number. In many situations it is practically useful to be able to 'coerce' the string to the corresponding number and then carry on as before, rather than raising an exception. (The situation usually arises only when external streams are being read, at least for languages which are statically typed, and thus where type consistency can usually be checked at compile time.) (Cardelli and Wegner 1985, provide an overview of typing in programming languages; Abadi et al. 1991 provide a formal treatment of type coercion showing how to model it within a typed lambda calculus language, while preserving soundness.)

We shall take this analogy quite literally, and model aspectual shift as a kind of type coercion. We shall think of the conceptual framework provided by aspectual categories as being exactly like a typing system. We can model the particular taxonomy we have chosen by taking three basic types: state, process, point, and allowing for a 'product type' constructor to form the complex types <point, state> and <process, state>. Temporal and aspectual modifiers will be thought of as operators that require inputs of a particular type and yield outputs of a particular type.

However, before exploring the formal details of this approach we will first quickly run through some central aspectual determination problems, and try to determine the various input and output type requirements involved. In doing so, we shall largely ignore the effect of arguments in combination with verbs (returning briefly below to the analyses of Verkuyl 1993, and Krifka 1987, 1991), concentrating on the effects of aspectual auxiliaries and temporal PP and Adv modifiers.

\section{Aspectual coercion}

In order to postpone discussion of argument coercion, we will use intransitive verbs and largely stick to simple proper name NP subjects. We will assume that our verbs are lexically specified as to which aspectual category they will be interpreted in by default. 'By default' here means, roughly, with singular definite arguments, and with no aspectual modifiers. Here are some example verbs in their default status interpretations: 
10 a Joe will sneeze. (point)

b Joe will swim. (process)

c Joe will win. (point/state)

d Joe will grow old. (process/state)

e Joe will be tall. (state)

Which category they are assigned to by default depends on at least the following criteria: temporal duration relative to some contextual baseline; perceived salience of consequent state; and whether or not a salient change is suggested. The assumption that this matter is lexically determined does not preclude a verb being assigned to more than one category: a more robust treatment might actually be to assign a probability distribution over each verb for each category.

Aspectual category will often shift when these basic forms are combined with (arguments or) modifiers: this is the process we refer to as 'coercion', where the resulting interpretation may have to be adjusted so as to make sense in a new ontological category. Our strategy will be to combine a particular operator with sentence radicals based on the different aspectual categories and to see which combinations sound good without special assumptions. These tell us what the required inputs for the operator are. Those that require coercions give us more information about the patterns of reconstrual that are necessary to ensure that typing requirements are met. We then apply the Vendler tests to the resulting combination to try to determine the output type.

\subsection{Progressive}

When we combine the present tense and the progressive aspectual marker in these sentences (with no explicit temporal modifiers), we get various possible differences of interpretation:

11 a Joe is sneezing

b Joe is swimming

c Joe is winning

d Joe is growing old

e Joe is being tall

Example (a) can most naturally mean either that Joe is in the process of sneezing just at that second, or that Joe is sneezing repeatedly. This is explained by the requirement that the progressive demands a process as input: points can be 'coerced' to processes either by 'stretching' them, or by 'iterating' them. Example (b) requires no coercion, in its most salient interpretation, because 'swim' is already a process. Process phrases are like mass terms in being 'homogeneous' (see Mourelatos (1978), Krifka $(1987,1991)$ ) and this is what licences the inference from 'joe is swimming' to 'joe has swum'. (As remarked above, this inference is 
subject to a 'granularity' limitation). (c) is most naturally interpreted as meaning that Joe is in the process of winning, but has not yet won. This requires two coercions: to focus on the point component of the <point, state> complex, and to stretch that point into a process. In (d) we focus on the process of a <process, state> complex, so only one coercion is required here.

The 'imperfective paradox' is the name given to the observation that there are inferential differences between process phrases and <point, state> or <process, state> phrases when in the progressive:

12 a 'Joe is swimming' implies 'Joe has swum'

b 'Joe is winning' does not imply 'Joe has won'

As with many others, I assume that this paradox is resolved by the fact that as a result of the coercions, it is not asserted by the (b) sentence that the resulting state is attained.

Phrases like 11(c) and (d) are not homogeneous. In fact, it is only on the iterative reading of 11(a), and for the process verb in (b) that we can get an entailment of the form ' $\mathrm{X}$ is $\mathrm{Y}$-ing $\rightarrow \mathrm{X}$ has $\mathrm{Y}$-ed'. In (e) we can only get a 'temporary role' reading with mildly comic effect. There is no regular way to coerce a state to a process, I assume, and so special assumptions and reasoning are required to make sense of such a sentence. However, this is a reading that is heard quite often: 'I'm being a manager at the moment, so I have no time for programming'.

As many people have noted, these coercions can be recombined. For example, when combined with a frequency expression sentence (a) can be interpreted as describing iterations of episodes that are themselves iterations:

13 Joe is sneezing like that every morning now.

Likewise, (b) - a process - can be coerced to a point and then iterated:

14 Joe is swimming every morning.

and the entire winning event in (c) coerced to a point and also iterated:

15 Joe is winning more often.

The same is even true of the (e) sentences: 'I'm being a manager in the mornings, and doing the real work in the afternoons'.

We will follow Moens and Steedman in regarding the progressive as being of type 'process $\rightarrow$ state'. The arguments for the input type being a process have just been given: that the output type is that of a state is suggested by the fact that a progressive meets all the usual tests for states given earlier (see Vlach 1981): a progressive (not subject to further coercions) does not advance the temporal reference point in a discourse; it cannot be further 'progressivised' (there are no progressives of progressives); they do not appear in imperatives; 
in the simple present there is present time reference (unless an explicit future adverbial is present).

\subsection{Perfect}

Moens and Steedman describe the perfect as something that requires its input to be a <point, state> complex (a 'culmination', in their terms) whose result is (usually) the corresponding consequent state. Thus the only sentence that would not require coercion is $(\mathrm{c})$ :

16 a Joe has sneezed.

b Joe has swum.

c Joe has won.

d Joe has grown old.

e Joe has been tall

For the remainder, the process of coercion that is necessary for the perfect to be felicitous is for the entire state or episode to be 'bundled' into a point, which then has a consequent state added. Thus (a) and (b) are acceptable if some relevant consequence of Joe having sneezed or swum is still at issue. As Moens and Steedman point out, one contextualisation that allows for this is where the events are part of some prearranged plan or expected outcome. (e) is odd, for the same reason that $15(\mathrm{e})$ was odd.

16(d) needs some comment: one might expect that the coercion involved would be to coerce the process component of the <process, state> complex to a point yielding something of the appropriate type. Moens and Steedman argue that the consequent state made salient by the use of the perfect in such cases is not identical to the state resulting from the former process: in an example like 'Joe has climbed Mt Everest', the state involved is not necessarily 'Joe on the summit of Mt. Everest', but the state (whatever it is) following the whole event. 16(d) seems to show that this is not always the case: it is possible to interpret this sentence along the lines they suggest, but it is surely also possible to interpret it as saying that the salient state here is that of Joe being old. Similarly, an example like:

17 Joe has baked a cake

has on its most salient interpretation that the state resulting from Joe's baking activities still persists. For these interpretations it does not seem necessary to reconstrue the process component of a <process, state> combination as a point: this, and other considerations we return to below, suggest that the appropriate input type for a perfect can be either a <point, state> or <process, state> combination, a pair of alternatives that we henceforth summarise as $\langle\mathrm{p} *$, state $\rangle$ 
Notice that it is not necessary for the state described by the perfect to correspond to any directly lexicalisable concept, although it is possible that the perfect may be more natural when it does. In some cases it is in fact rather difficult to find a non-trivial description of the state implied by use of the perfect.

Moens and Steedman's treatment of perfect and progressive does not make the combination of the two a natural possibility, since, if their semantic composition follows syntactic structure, the input to the perfect will always be a state, namely the state resulting from the application of the progressive.

18 a Joe has been sneezing.

b Joe has been swimming.

c Joe has been winning.

d Joe has been growing old.

e Joe has been being tall

This state will need to be coerced first to a point, then to a state resulting from that point. Thus the interpretation of (a) will be as a description of the state resulting from the previous episode of Joe sneezing. This episode in turn may have been an iteration or a stretch. (b) is interpreted as describing the state following from the process of Joe swimming seen as a point. (c) can be interpreted as describing the state resulting from an iteration of winnings (seen as a point), or as that resulting from the preparatory phase (stretched from a point to a process). In the former case, it will follow from (c) that Joe has won (at least once) whereas it will not in the latter case. The latter case needs a more elaborate context: a 24 hour race, for example, where Joe was in the lead for a while. In principle, (d) would have two analogous interpretations, but the one involving iteration is eliminated unless used in a science fiction or reincarnationist context. (e) is interpreted as predicted, and as with even the simplest examples of this type of coercion needs a special context.

The reasoning as to why the output of a perfect is a state is exactly as for the progressive: a perfect does not advance a temporal reference point in a discourse; there are no progressives of perfects, and there are no perfect imperatives. The 'present time reference' test is not obviously applicable, although in the present, there is clearly implicit reference to the consequent state holding at the present time.

\section{3 $\quad$ For+time-period}

Moens and Steedman characterise temporal adverbials like 'for an hour', 'for 3 weeks', or 'for a long time' as requiring a process as input, yielding a <process, state> expression as output. The requirement for the input to be a process is based on the interpretations of (a) to $(d)$ : 
19 a Joe sneezed for an hour.

b Joe swam for an hour.

c Joe won for an hour.

d Joe grew old for many years.

e Joe was tall for a year

Example 19(a) requires either stretching or iteration to a process to be sensible; (b) is fine without coercion; (c) is only acceptable on a reading where we coerce first to a point, then to an iteration; and (d) is odd on what should be the primary interpretation because it cannot be iterated for pragmatic reasons. In fact, there is another interpretation for (d) where only the process component of the <process, state> complex is modified.

Example (e) shows that Moens and Steedman are not quite correct to claim (p20) that for-adverbials can only combine with process expressions. Admittedly, this particular example is odd for pragmatic reasons, but other state expressions can combine unproblematically with such phrases. This, and the fact that these modifiers can be interpreted as describing only the process component of a complex like (d), might lead us to look also for other interpretations for expressions like (c) and (d), interpretations on which the modifier modifies only the state component:

20 a Joe hired a car for a week.

b Joe pitched a tent for a week.

Moens and Steedman argue on cross-linguistic grounds that this is a different sense of 'for'. It is true that these different interpretations might be translated differently in French or German. But this in itself does not show that there are two senses of 'for' in English, merely that a structural ambiguity - in a wide sense - in one language is resolved lexically in another. (See Dowty 1979:56, and Pustejovsky 1991:73, who both agree with us in regarding this type of example as demonstrating that both components of a complex eventuality can be independently temporally modified. Other arguments for this point of view can be made using adverbs like 'again' and temporal conjunctions like 'until': Dowty 1979: 250ff)

The argument Moens and Steedman make for the output of 'for' adverbials being a <process,state> (culminated process in their terms) is that this output is suitable input to the perfect (p20), pointing to the difference in acceptability between:

21 a ? John has worked in the garden

b John has worked in the garden for five hours

However, this is inconsistent with their earlier claim (p19) that the input category to perfects is actually a culmination (<point, state>). Since the combination of 'for' with perfect does seem to be quite natural, at least when the coercions involved in the interpretation of the adverbial itself are not too complex: 
22 a Joe has sneezed for an hour.

b Joe has swum for an hour

c Joe has won for an hour

d Joe has grown old for a year

e Joe has been tall for a year

we will assume that this is further evidence for our revised view of the perfect as being of type '<p*, state> $\rightarrow$ state'.

For this explanation to work, the perfect must be interpreted as an operator on the modified VP, rather than the adverbial modifying the perfect VP. The latter combination, in terms of typing requirements, would be perfectly natural, given the ability of 'for'-phrases to take states as well as processes as input. But we do not observe the interpretation that would be associated with this structure, namely that the duration of the state produced by the perfect was that described by the 'for' phrase. We return below to the question of the relation between syntactic structure and aspectual composition.

Note that the various tests for a <process, state> category do not all give unequivocal results. Further modification with another 'for' phrase does need special context; but so does modification with 'in'; ' $\mathrm{X}$ is now V-ing for time $\mathrm{T}$ ' does not entail ' $\mathrm{X}$ has V-ed for time T', correctly; but examples of the form ' $\mathrm{X}$ V-ed for time T1 in time T2' seem to need so much coercion that it is difficult to find a plausible enough candidate to test whether it entails ' $\mathrm{X}$ was $\mathrm{V}$-ing during time T2'. Perhaps a pair like the following show that this entailment does hold if a suitable instance can be found:

23 a Joe swam for five minutes in the half-hour period

b Joe was swimming for five minutes during the half-hour period

\subsection{In+time-period}

Moens and Steedman characterise adverbials like 'in less than 60 seconds', 'in a year', as well as expressions like 'take 3 minutes to ...', as requiring a <process , state> complex as input. They do not say explicitly what the output type is but their examples suggest that it is a <point, state> or in their terms, a 'culmination'. Of the following, therefore, only (d) will have an uncoerced interpretation.

24 a Joe sneezed in less than 30 seconds

b Joe swam in less than 30 seconds

c Joe won in less than 30 seconds

d Joe grew old in less than 3 years

e Joe was tall in less than 3 years

For (a) we have to be able to coerce a point into a <process, state> complex. There are two ways to achieve this: first, the point can be stretched to a process, 
and then have a consequent state added. This interpretation is not contextually plausible, unless Joe habitually takes almost a minute to sneeze: we need to invoke slow-motion films and other tricks. Changing '30 seconds' to '30 msec' makes it an obtainable reading. The consequent state begins at the end of the time period mentioned.

The second interpretation available may provide some evidence that we do need a separate notion of culmination point after all. In this interpretation it is not entailed that the process component lasts for (a fraction less than) 30 seconds, but rather that the entire event happened within (and by conversational implicature, at the end of) the time period mentioned. To get this interpretation we need to have a preparatory process added for an entire sneezing event (a possible context might be one in which the people are testing varieties of snuff for rapid effect). The coercion functions we have employed so far will not achieve this, as stated: we could add a preparatory process, but that would give us a complex not otherwise observed: a <process, point> combination. This is still not valid input to the adverbial. We have no mechanism for turning points into states.

This is where the possible role of explicit culmination points might help: if what we are calling <process, state> complexes are really (as for Moens and Steedman, Kamp and Reyle and others) <process, culmination_point, state> complexes, then it is quite plausible to think of adding both a preparatory process and a consequent state to a point. (When Moens and Steedman describe an event nucleus as having the structure 'preparatory process, culmination, consequent state', it is not clear to me whether 'culmination' is here intended to be the same conceptual category as in their phrase classification.)

However, I am not convinced that this is the correct analysis of these sentences. I think that it is at least arguable that this interpretation reflects an ambiguity of 'in' adverbials noticed by Dowty (p334-335). In this interpretation, the event described is being located during (or by implicature) at the end of the described period of time, and there must, as Dowty observes, also be a way of identifying the start of the period. The start point can be explicitly supplied:

25 Joe sneezed in less than 30 seconds from taking the snuff

and if it is not explicitly supplied it must be 'accommodated' in the context. As Dowty pointed out, if the adverbial is preposed, only this interpretation is present.

What Moens and Steedman interpret as the addition of a preparatory phase, then, is actually the contextual provision of a start point. If this analysis is correct, then we do not need explicit culmination points: at least, this is the only place where it seems difficult to do without them. On this interpretation of 'in' it seems to be of of type 'point $\rightarrow$ <point, state> ', coercing its input by 'bundling' it if it is not already a point: 
26 a In less than 30 seconds, Joe sneezed.

b In less than 30 seconds, Joe swam.

c In less than 30 seconds, Joe won.

d In less than 3 years, Joe grew old.

e In less than 3 years, Joe was tall.

We can analyse the sentence as saying that the input point derived by coercion from the basic event is located 30 seconds from the contextually determined start point. I shall therefore continue to assume that we can get by with the simpler view of event structure, at the cost of assuming an ambiguity for 'in', on which extra interpretation it is more like 'within'.

For 25(b), ignoring an elliptical reading on which it has the appropriate input type, there are two possible interpretations. On the first, we add a consequent state to the process, and the swimming itself lasts for 30 seconds. A possible context would be one in which there is some prearranged sequence of sporting activities: a triathlon, perhaps, which includes some swimming. On the other reading, on the Moens and Steedman account, we add a preparatory process, turning the original process to a point, and adding a consequent state. On this interpretation the preparatory process took 30 seconds. On our account, we simply interpret it as meaning 'within less than 30 seconds from the starting time'. A possible context would be swimmers bracing themselves for the traditional Christmas day swim on Brighton beach; or, with a longer time period, children learning to swim.

To interpret (c) we need to coerce the point of the <point, state> complex to a process. (d) is unproblematic. (e) requires a preparatory process to be added, on Moens and Steedman's story, which is difficult to contextualise. On our account there is some contextually supplied starting point (taking growth hormones?). For other state sentences, the interpretation is easier:

27 Joe lived in Amsterdam in 3 years

- after 3 years, measured from some starting point, of trying to achieve this state of affairs, Joe finally managed it. As we might expect, this interpretation is easier when the PP is preposed.

Do the various achievement tests apply to the output of modification by 'in'? It is certainly not possible to modify the result with 'for+time period' without further coercion; it may not be possible to further modify by a further occurrence of 'in + time period' without contradiction:

28 Joe ran a mile in four minutes in five minutes

The only interpretation for sentences like this requires the 'in five minutes' to have the alternative interpretation just discussed. For the same reason, the entailment test is difficult to apply here. Thus the evidence for the output type of in + time 
period' being a '<point, state>' somewhat indirect: the best clue is that when it is input to the perfect (which is ' $\langle\mathrm{p} *$, state $>\rightarrow$ state ') we do not seem to need any coercions:

29 Joe has run a mile in four minutes

suggesting that it is an appropriately typed input.

\section{Argument coercion}

As well as optional temporal modifiers, arguments also affect the aspectual status of phrases. The main parameter is, roughly speaking, whether an argument is 'quantized' or not (Verkuyl 1989, 1993; Krifka 1987:155, 1991), that is, whether it refers to a specific quantity or not; and whether the verb expresses, roughly speaking, change of state or progress over time. In general, the following types of NP are quantized:

Singular referential definites, indefinites, demonstratives, possessives, NPs with (non-negative) quantifiers or numeric determiners.

Non-quantized NPs are, in general:

Those with negative determiners ('no...', 'none of the...'), bare plurals, mass terms, attributive definites, some plural definites.

Notice that the status of an NP in this respect cannot always be determined on the basis of form, but on its referential properties in a particular context of occurrence.

In this picture, verbs are categorised according to their intrinsic semantic properties. For example, a verb like 'eat' expresses change (is +SQA, in Verkuyl's terminology), whereas a verb like 'see' generally does not.

The effect of the status of arguments can be seen in examples like:

30 a John drank wine for an hour/*in an hour

b John drank a glass of wine ?for an hour/ in an hour

31 a The soldier arrived *all morning

b The soldiers arrived all morning

In subject position, the effect of an unquantized NP is to make a 'process' interpretation much more accessible for point or <point, state> verbs:

32 a The men sneezed for an hour

b The men won for an hour 
The same thing is true in object position:

33 a The men built houses for a year

b The men won races for a month

Jackendoff, in various places (e.g. Jackendoff 1991), and Pustejovsky (among others) have also pointed out that aspectual status can change under the influence of non-temporal modifiers. Thus whereas:

34 Joe ran

is a process, a sentence like:

35 Joe ran to the shop

has the properties of a <process, state> combination. This is perhaps easier to see in the progressive, where the 'imperfective paradox' property is apparent:

36 a Joe is running implies Joe has run

b Joe is running to the shop does not imply Joe has run to the shop

I do not propose to discuss argument composition in detail. It appears to me that some development of the mechanisms proposed in Krifka 1992, or in Verkuyl 1993 can be adapted and suitably integrated with what is proposed here for temporal modifiers. At the level at which we are concerned, the relevant generalisations concerning argument coercions can either be stated semi-compositionally in terms of semantic interpretation rules for VPs and Ss, or in terms of the coercion mechanism we develop below. For the cases of coercion induced by non-temporal modifiers, I will assume that a treatment analogous to that we will provide for temporal modifiers will be required.

\section{Syntax and aspectual composition}

Clearly the composition of a verb with its arguments is governed by syntax. But is aspectual composition in general governed by syntax?

In an earlier section, we referred to an argument by Moens and Steedman that the output of 'for' adverbial modification was a $\langle$ process, state $\rangle$, since it was a valid input to the perfect:

37 Joe has swum for an hour

If aspectual composition follows syntactic structure, as Moens and Steedman claim (although with some qualification: p22) then this argument seems to presuppose that the perfect auxiliary has scope over the modified VP:

38 a Joe [has [swum for an hour]]

b Joe [[has swum] for an hour] 
i.e. as in (a) rather than (b). But in fact the easiest way of assembling the semantics from such a structure would yield the result that the parse in which the perfect has scope over the adverbial has the reading in which the time span of the adverbial is (entirely) in the past with respect to the time of utterance. This is not the most salient reading of example 37, and I do not think it is the one that Moens and Steedman are assuming.

Many people have noticed that sentences like this, or:

39 Mary has lived in Amsterdam for 5 years

are in fact ambiguous between interpretations where the end of the 5 year stretch is the time of utterance, or at some time in the past (Dowty 1979:343; Kamp and Reyle 1993:567; Hitzeman 1994; 1996). It would seem natural to associate this difference with the two alternative syntactic analyses that seem to be available, on which the PP attaches either to the VP headed by the main verb, or to that headed by the auxiliary. This might seem to support the notion that aspectual composition follows syntax.

In fact, the picture is more complex. The preposed version:

40 For 5 years, Mary has lived in Amsterdam

appears at first sight to only have the reading in which the five years ends at utterance time. Hitzeman argues that a range of adverbials have the same property, and that this reading is associated with PP attachment at S level (1996:3). But this cannot be correct, for the reading is available in:

41 Mary has lived in Amsterdam for 5 years but only worked with the company for 2 .

where it is clear that the syntactic structure has to be:

$\ldots$ [has [[VP1 for 5 years] but [VP2 for 2]]]

precluding the possibility of $\mathrm{S}$ attachment. In fact, BOTH readings are available in 41 , even though only one syntactic attachment point is possible. This suggests that syntax does not restrict the possibilities in the way we assumed. I agree with Hitzeman, however, that information structure is involved: I think the correct explanation is that the prior-to-utterance-time interpretation is only possible when 'lived in Amsterdam for 5 years' is given information:

42 a Has anybody here ever lived in Holland for more than a year?

b Mary has lived in Amsterdam for 5 years

The preposed version does not have this interpretation, because the topicalisation splits the VP into two components, and gives each a different information status: this is the point of topicalisation, of course. 
Further evidence that aspectual composition is not wholly syntax-governed comes from combinations of adverbials like:

43 Joe sneezed twice in 30 seconds

This can have the interpretation that there were two sneezes within 30 seconds, or that Joe won the how-long-does-it-take-the-snuff-to-work competition twice, each time with a performance of 30 seconds. It is not plausible to find a syntactic ambiguity here. Preposing the adverbials, as we have in part already seen, produces a strong bias for one interpretation or another:

44 a Twice Joe sneezed in 30 seconds

b In 30 seconds Joe sneezed twice

but almost as strong is the effect of intonational focus:

45 a Joe sneezed TWICE in 30 seconds

b Joe sneezed twice in 30 SECONDS

It seems safe to conclude that aspectual composition (like quantifier scope) is influenced but not wholly determined by syntactic structure. Information structure is probably the primary other determinant. This suggests that the interface to a computational 'aspectual coercion' module should not be a syntactic structure or rule tree, with lexical meanings at the leaves (as would be appropriate for compositional semantics) but a function-argument structure or a partly resolved quasi-logical form (Alshawi 1990), which would itself be the result of some prior contextual reasoning. This prior processing would be responsible for working out information structure, and also resolving ellipsis and pronoun references, since for the kind of NP argument compositions decribed in the previous section, knowing whether a definite NP or a pronoun should be interpreted as quantized or non-quantized would be necessary input to the coercion module:

46 a Joe ordered a beer

b He drank it in/?for a few moments

c Joe ordered beer

d He drank it for a few moments

Similarly, knowing whether the b sentence below should be interpreted as elliptical or not affects the acceptability of the modifier:

47 a John walked home in an hour

b Mary drove (home) in five minutes

\section{An analysis in terms of type coercion}

We have an intuitive hierarchy of the kinds of eventualities described by sentences: 


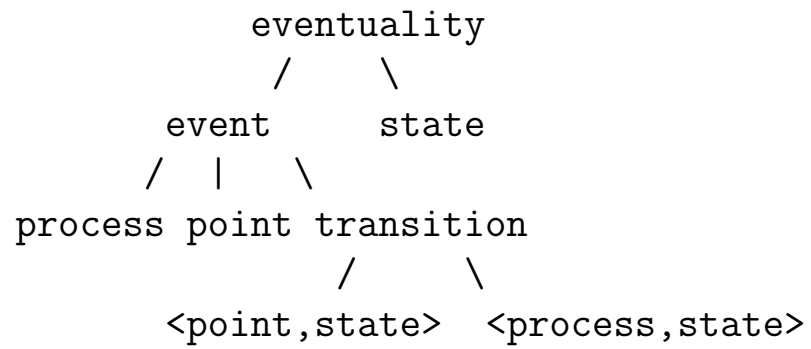

If we are to model the phenomenon of aspectual shift as a form of type coercion then we first need to fix our type system. We will have the usual base types e and t, but will subdivide e, the domain of individuals, into 'things' (the usual things of type e) along with 'eventualities' that we shall describe as point, process , and state, and we shall assume a product type constructor that allows us to form the transition types <point, state> and <process, state>. It will also be convenient to be able to refer to the supertypes event (e), eventuality (ev), and transition (<p*, state $>$ ) indicated in the hierarchy above.

As well as this basic ontological repertoire there are a variety of 'coercion' operators which allow one type of event or state to be viewed as another. These are:

iterate: point $\rightarrow$ process

You can iterate a point event to become a process consisting of more than one occurrence of the event. As many authors have commented (see Jackendoff 1991:16, and references discussed there), this is essentially a pluralisation operator: in the case where the subject of the event is singular, real world constraints enforce the interpretation that the repetitions are sequential rather than simultaneous. When the subject is plural already, there is no such constraint.

stretch: point $\rightarrow$ process

You can 'stretch' the internal structure of a point event so that it is viewed as a process. This can apply to the point component of a <point, state> complex, too. Again, as many authors have pointed out, this is the event version of the 'universal grinder' that turns count nouns into mass nouns.

bundle: $\mathrm{X} \rightarrow$ point, where $\mathrm{X}$ is not a point

You can bundle up anything not already a point and ignore its internal structure. (This is the 'universal packager' for events. There is some dispute over the precise origin of these useful terms: see Jackendoff 1991: 24, fn 11).

pphase-of : <X, state> $\rightarrow X$, where $X$ is point or process

You can focus on a preparatory phase of an event, ignoring its consequent state, which is then not necessarily asserted as holding. 
cstate-of $\langle$ X, state $>->$ state

You can focus on a consequent state of an event. However, the preparatory phase is still asserted to hold, for otherwise the consequent state could not hold.

add-cstate: $\mathrm{X} \rightarrow\langle\mathrm{X}$, state $>$, where $\mathrm{X}$ is point or process

You can also add consequent states to events where they are not already salient.

Particular modifiers are also typed, in the sense that they require what they modify to have a particular aspectual status, and yield typically another aspectual status for the combined expression. Our earlier discussion suggests the following type assignments:

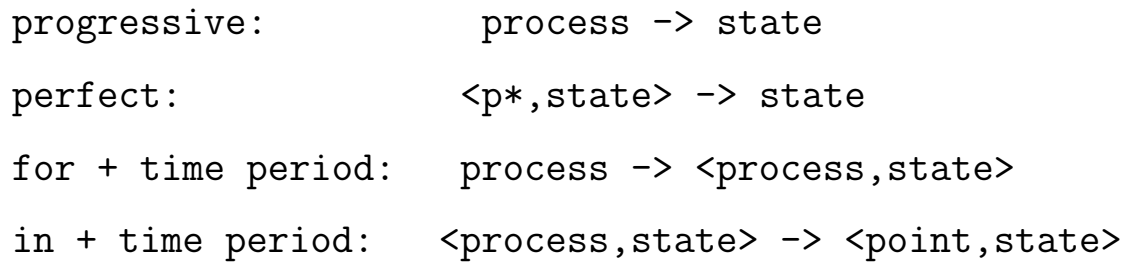

(Notice that Moens and Steedman distinguish different types of state for the 'prog' and 'perf' operators). Other adverbials can be typed in a similar way: for example, 'frequently' and 'every day' would be event $\rightarrow$ process; 'on Friday' might be X $\rightarrow$ point; 'until Friday' might be \{process | state\} -> <process, state>, etc. This typing may itself be partly compositionally determined, of course. (Notice that the assignment for 'until time point' could be more succinctly expressed if we could generalise over processes and states, which it would be easy to arrange).

Conjunctions may also be typed in a similar way. For example, temporal 'then' seems to require its input to be a point, with the effect that even sentences that in isolation would be understood as states will be understood as events:

48 First, the dog ate my exercise book.

Then, I was ill.

So I didn't get my essay in on time

A sentence like 'I was ill' would normally be taken to describe a state and thus not advance temporal reference. See Kamp and Reyle (1993: 508) for discussion of similar cases. Conjunctions like 'before', 'after' and 'when', however, seem to accept more or less any type of eventuality, although exactly which aspectual category is assigned will have a marked influence on their precise interpretation, as Moens and Steedman point out.

Tenses do not affect aspectual status, per se, although of course they interact with it in subtle and complicated ways. However, I will abstract away from any discussion of these interactions in what follows. 


\section{Model Theory for Aspectual Coercion}

It has proved remarkably difficult to integrate descriptions of aspectual coercion with the main tradition of formal semantic description. Moens and Steedman provide a transition network formalisms which describes the possible aspectual coercions allowed by in their theory, but the exact semantics of this device is not specified. In later work, Steedman (1996) provides a computational illustration of some types of aspectual coercion, using a framework which borrows elements from planning, non-monotonic reasoning, and logic programming, in what amounts to essentially a proof-theoretic account. Other authors, like Pustejovsky (1991), and particularly Jackendoff (1991), provide suggestive representations in their discussion of some of these phenomena, but do not supply any explicit semantics for these representations. Pustejovsky and Bouillon (1996) assume the existence of a family of coercion functions within the framework of the 'generative lexicon' model in describing the interpretation of aspectual verbs like 'start' or 'commencer', but do not go into any detail on the model theory underlying this.

Krifka $(1987,1991)$ and Verkuyl (1993) are welcome exceptions in that they attempt to provide an explicit model-theoretic analysis of argument coercion. Krifka uses a lattice-based approach deriving from the analysis of plurals, and Verkuyl uses generalised quantifier theory to construct meaning representations that distribute predicates over sets in various ways.

In what follows, I shall try to develop an explicit syntactic and semantic fragment in which many of the aspectual phenomena discussed earlier can be accurately described. Since the formal framework I am assuming is in many important respects compatible with those assumed by Krifka and Verkuyl I shall assume that many of the insights of these two authors can be integrated into the present

scheme. However, I shall not go into this matter in any detail, restricting myself largely to an account of aspectual coercions associated with aspectual auxiliaries and temporal modifiers.

First we turn to the model theory needed. Our starting point will be the kind of models provided for the treatment of tense and aspect in DRT (Kamp and Reyle p667 ff). The basic components are (as well as a set of ordinary individuals) a set of eventualities (events and states), and over them a temporal precedence relation, $<$, which is irreflexive, asymmetric, and transitive; and an 'overlap' relation ' $\mathrm{O}$ ', which is symmetric, reflexive, and non-transitive. The ' $\mathrm{O}$ ' and < relations are connected by the following axioms (p667):

P5: $\mathrm{e} 1<\mathrm{e} 2 \rightarrow \neg \mathrm{e} 1 \mathrm{O}$ e2

P6: e1 < e2 \& e2 O e3 \& e3< e4 $\rightarrow$ e1 < e4

P7: e1< e2 $\vee$ e1 O e2 $\vee$ e2 $<$ e1 
There is also a relation on eventualities of inclusion, $\subseteq$ :

$$
\mathrm{e} 1 \subseteq \mathrm{e} 2 \text { iff } \forall \mathrm{e} .(\mathrm{e} 2<\mathrm{e} \rightarrow \mathrm{e} 1<\mathrm{e}) \vee(\mathrm{e}<\mathrm{e} 2 \rightarrow \mathrm{e}<\mathrm{e} 1)
$$

and relations of temporal equivalence, $\equiv$, and of 'abutment' or 'spatiotemporal adjacency' $(x)$. The latter relation can be glossed as saying that 'ev1 $\chi$ ev2' means that ev2 begins just as ev1 ends.

We also assume a parallel 'instant structure' from which we can construct intervals, and a function LOC that maps events to intervals and which preserves the properties of < and O. From the relation $\equiv$ on intervals and moments we can further construct a notion of 'amounts of time', which serve as the denotations of temporal phrases like 'one hour', 'three weeks', etc.

So far, all of this is exactly as in Kamp and Reyle. In order to accommodate aspectual coercion phenomena, however, we have to further elaborate these models. We first extend them by further subdividing the category of events into points and processes, and adding new derived types of complex transition events. Thus a model will consist of a structure

$\langle$ Eventualities, Instants, Individuals, LOC, $\equiv, \mathbf{I}\rangle$

'Eventualities' consists of Points, Processes, States, and Transitions, where Transitions are those members of the product types '(Points $U$ Processes $) \times$ States' that satisfy the abutment relation. They will thus be of the form $\left\langle\mathrm{e}_{p t}, \mathrm{f}_{s t}\right\rangle$ or $\left\langle\mathrm{e}_{p r}\right.$, $\left.\mathrm{f}_{s t}\right\rangle$ such that e $\mathcal{X}$.

Instants are moments of time (from which intervals and amounts of time are constructed), Individuals are entities that aren't Eventualities or Instants, LOC and $\equiv$ are as described above, and $\mathbf{I}$ is an interpretation function for the logical language that we shall now describe.

Intransitive verbs like 'sneeze' or 'swim' we shall assume are lexically marked for their default aspectual category. Transitive verbs we shall assume to be marked with something equivalent to Verkuyl's 'SQA' feature, and when they are combined with their complement, the relevant semantic rule will assign the resulting VP to the appropriate aspectual category, depending upon the properties of the complement and the verb. A similar process will account for the combination of subjects with all types of verb phrases.

We can now provide interpretations ('I') for point, process, and state predicates as follows. Types of eventualities (for which we use 'e, $f, g, \ldots$ ') are indicated by subscript, and the notation ' $\overrightarrow{\mathrm{x}}$ ' is a shorthand for ' $\mathrm{x}_{1} \ldots \mathrm{x}_{n}$ ', where the $\mathrm{x}$ 's are of type Individual, 'n' varying according to the arity of the predicate involved.

A Where $\mathrm{P}$ is a point predicate, then $\mathbf{I}[\mathrm{P}]$ is a set of tuples $\left\langle\mathrm{e}_{p t}, \overrightarrow{\mathrm{x}}\right\rangle$.

(and analogously for process and state predicates) 
We can construct the complex aspectual types using transitions as defined above:

$\mathrm{B}$ Where $\mathrm{P}$ is a <point, state> predicate, then $\mathbf{I}[\mathrm{P}]$ is a set of tuples $\left\langle\mathrm{e}_{\langle p t, s t\rangle}, \overrightarrow{\mathrm{x}}\right\rangle$, where $\mathrm{e}_{\langle p t, s t\rangle} \equiv\left\langle\mathrm{f}_{p t}, \mathrm{~g}_{s t}\right\rangle$ such that $\mathrm{f} \mathcal{X g}$, - and analogously for <process, state> predicates.

Now we can provide interpretations for the coercion functions, in terms of clauses which extend the original model. (Notice that the complete model is now defined by a set of recursive statements, in a way familiar from the semantics of programming languages: Stoy 1977).

C When $\left\langle\mathrm{e}_{p t}, \overrightarrow{\mathrm{x}}\right\rangle$ is in $\mathbf{I}[\mathrm{P}]$, then there is a process $\mathrm{f}_{p r}$ such that $\left\langle\mathrm{f}_{p r}, \overrightarrow{\mathbf{x}}\right\rangle$ is in $\mathbf{I}[$ iterate $(\mathrm{P})]$, and there are at least two distinct points $\mathrm{g}_{p t} \subseteq \mathrm{f}_{p r}$ and $h_{p t} \subseteq \mathrm{f}_{p r}$, such that $\left\langle\mathrm{g}_{p t}, \overrightarrow{\mathrm{x}}\right\rangle$ and $\left\langle\mathrm{h}_{p t}, \overrightarrow{\mathrm{x}}\right\rangle$ are in $\mathbf{I}[\mathrm{P}]$.

$\mathrm{D}$ When $\left\langle\mathrm{e}_{p t}, \overrightarrow{\mathrm{x}}\right\rangle$ is in $\mathbf{I}[\mathrm{P}]$, there is a process $\mathrm{f}_{p r} \subseteq \mathrm{e}_{p t} \mathrm{such}$ that $\left\langle\mathrm{f}_{p r}, \overrightarrow{\mathbf{x}}\right\rangle$ is in $\mathbf{I}[\operatorname{stretch}(\mathrm{P})]$.

The process $\mathrm{f}$ is $\subseteq$ e rather than $\equiv$, since, for example, in a progressive a 'stretched' event may not be completed.

$\mathrm{E}$ When $\langle\mathrm{e}, \overrightarrow{\mathrm{x}}\rangle$ is in $\mathbf{I}[\mathrm{P}]$, where e is not a point , there is a point $\mathrm{f}_{p t} \equiv$ e such that $\left\langle\mathrm{f}_{p t}, \overrightarrow{\mathbf{x}}\right\rangle$ is in $\mathbf{I}[\operatorname{bundle}(\mathrm{P})]$.

$\mathrm{F}$ When $\left\langle\mathrm{e}_{\langle p t, s t\rangle}, \overrightarrow{\mathrm{x}}\right\rangle$ is in $\mathbf{I}[\mathrm{P}]$, where $\mathrm{e}_{\langle p t, s t\rangle}=\left\langle\mathrm{f}_{p t}, \mathrm{~g}_{s t}\right\rangle$, then $\left\langle\mathrm{f}_{p t}, \overrightarrow{\mathbf{x}}\right\rangle$ is in $\mathbf{I}[$ pphase-of $(\mathrm{P})]$

- and analogously where the transition is of the form $\mathrm{e}_{\langle p r, s t\rangle}$

Notice that the denotation of 'pphase-of(P)' does not include the consequent state. Depending on the construction, this may or may not also be asserted as holding.

$\mathrm{G}$ When $\left\langle\mathrm{e}_{\langle p t, s t\rangle}, \overrightarrow{\mathrm{x}}\right\rangle$ is in $\mathbf{I}[\mathrm{P}]$, and $\mathrm{e}=\left\langle\mathrm{f}_{p t}, \mathrm{~g}_{s t}\right\rangle$ then $\left\langle\mathrm{g}_{s t}, \overrightarrow{\mathbf{x}}\right\rangle$ is in $\mathbf{I}[$ cstate-of $(\mathrm{P})]$

- and analogously where the transition is of the form $\mathrm{e}_{\langle p r, s t\rangle}$

Notice that the denotation of 'cstate-of(P)' does not include the preparatory phase. However, every construction in which this coercion operator is used also asserts that the preparatory phase holds.

$\mathrm{H}$ When $\left\langle\mathrm{e}_{p t}, \overrightarrow{\mathbf{x}}\right\rangle$ is in $\mathbf{I}[\mathrm{P}]$, then there is a state $\mathrm{f}_{s t}$, e $\mathcal{X}$, such that $\left\langle\mathrm{e}_{p t}, \mathrm{f}_{s t}\right\rangle=\mathrm{g}_{\langle p t, s t\rangle}$, and $\left\langle\mathrm{g}_{\langle p t, s t\rangle}, \overrightarrow{\mathrm{x}}\right\rangle$ is in $\mathbf{I}[\operatorname{add}-\operatorname{cstate}(\mathrm{P})]$ - and analogously for $\mathrm{e}_{p r}$.

I When $\left\langle\mathrm{e}_{p r}, \overrightarrow{\mathrm{x}}\right\rangle$ is in $\mathbf{I}[\mathrm{P}]$, then there is a state $\mathrm{f}_{s t} \subseteq \mathrm{e}_{p r}$, such that $\left\langle\mathrm{f}_{s t}, \overrightarrow{\mathbf{x}}\right\rangle$ is in $\mathbf{I}[\operatorname{prog}(\mathrm{P})]$.

This is essentially the same definition of the contribution of the progressive as in 
Kamp and Reyle.

$\mathrm{J} \quad$ When $\left\langle\mathrm{e}_{\langle p t, s t\rangle}, \overrightarrow{\mathrm{x}}\right\rangle$ is in $\mathbf{I}[\mathrm{P}]$, and $\mathrm{e}_{\langle p t, s t\rangle}=\left\langle\mathrm{f}_{p t}, \mathrm{~g}_{s t}\right\rangle$ then $\left\langle\mathrm{g}_{s t}, \overrightarrow{\mathbf{x}}\right\rangle$ is in $\mathbf{I}[\operatorname{perf}(\mathrm{P})]$

- and analogously where the transition is of the form $\mathrm{e}_{\langle p r, s t\rangle}$.

Again, we have to ensure that the preparatory phase is also asserted as holding.

Note that all of the coercion operators so far will be of the general type $\left\langle\left\langle\mathrm{e},\left\langle\mathrm{i}^{*}, \mathrm{t}\right\rangle\right\rangle,\left\langle\mathrm{e},\left\langle\mathrm{i}^{*}, \mathrm{t}\right\rangle\right\rangle\right\rangle$, where ' $\mathrm{e}$ ' is the type of eventualities (more specific subtypes will be as indicated above), ' $i$ ' and ' $t$ ' the types of individuals and truth values. ' $i$ '' is a shorthand for $\langle i,\langle i, \ldots\rangle$.$\rangle , the precise structure of which will vary depending on the arity of$ the predicate involved.

We have two clauses for 'for' to accommodate the observation that it can apply to states as well as processes:

$\mathrm{K}$ When $\left\langle\mathrm{e}_{p r}, \overrightarrow{\mathrm{x}}\right\rangle$ is in $\mathbf{I}[\mathrm{P}]$, and $\mathrm{T}$ denotes an amount of time, then there is some $\mathrm{f}_{s t}$ such that $\mathrm{g}_{\langle p r, s t\rangle}=\left\langle\mathrm{e}_{p r}, \mathrm{f}_{s t}\right\rangle$

and $\left\langle\mathrm{g}_{\langle p r, s t\rangle}, \overrightarrow{\mathbf{x}}\right\rangle$ is in $\mathbf{I}[\operatorname{for}(\mathrm{T}, \mathrm{P})]$.

$\mathrm{L}$ When $\left\langle\mathrm{e}_{s t}, \overrightarrow{\mathrm{x}}\right\rangle$ is in $\mathbf{I}[\mathrm{P}]$, and $\mathrm{T}$ denotes an amount of time, then there is some $\mathrm{f}_{p r} \equiv \mathrm{e}_{s t}$, some $\mathrm{g}_{s t}$ and $\mathrm{h}_{\langle p r, s t\rangle}=\left\langle\mathrm{f}_{p r}, \mathrm{f}_{s t}\right\rangle$ and $\left\langle\mathrm{h}_{\langle p r, s t\rangle}, \overrightarrow{\mathrm{x}}\right\rangle$ is in $\mathbf{I}[\operatorname{for}(\mathrm{T}, \mathrm{P})]$.

Likewise, we have two clauses for 'in'. The types of the functors 'for' and 'in' will be $\left\langle\mathrm{amt},\left\langle\mathrm{e},\left\langle\mathrm{i}^{*}, \mathrm{t}\right\rangle\right\rangle,\left\langle\mathrm{e},\left\langle\mathrm{i}^{*}, \mathrm{t}\right\rangle\right\rangle\right\rangle$, where 'amt' is the type of 'amounts of time'.

M When $\left\langle\mathrm{e}_{\langle p r, s t\rangle}, \overrightarrow{\mathrm{x}}\right\rangle$ is in $\mathbf{I}[\mathrm{P}], \mathrm{T}$ denotes an amount of time, then there is some $\mathrm{f}_{p t}, \mathrm{e}_{\langle p r, s t\rangle} \subseteq \mathrm{f}_{p t}$, and some $\mathrm{g}_{s t}, \mathrm{~h}_{\langle p t, s t\rangle}$ such that $\left\langle\mathrm{h}_{\langle p t, s t\rangle}, \overrightarrow{\mathbf{x}}\right\rangle$ is in $\mathbf{I}[\operatorname{in}(\mathrm{T}, \mathrm{P})]$

$\mathrm{N}$ When $\left\langle\mathrm{e}_{p t}, \overrightarrow{\mathrm{x}}\right\rangle$ is in $\mathbf{I}[\mathrm{P}], \mathrm{T}$ denotes an amount of time, then there is some $\mathrm{f}_{s t}$, some $\mathrm{g}_{\langle p t, s t\rangle}$ where $\mathrm{g}_{\langle p t, s t\rangle}=\left\langle\mathrm{e}_{p t}, \mathrm{f}_{s t}\right\rangle$ such that $\left\langle\mathrm{g}_{\langle p t, s t\rangle}, \overrightarrow{\mathbf{x}}\right\rangle$ is in $\mathbf{I}[\mathrm{in}(\mathrm{T}, \mathrm{P})]$

\section{A Fragment}

To illustrate the approach, we will define a syntactic and semantic fragment capable of assigning appropriate interpretations to sentences of the type we have been discussing. We will abstract away from tense, and assume that sentence meanings are predicates on events. We will ignore quantified NP meanings, treating all NPs as simple and unanalysed terms denoting individuals, amounts of time, etc. We will ignore the internal structure of unmodified VPs, and assume some analysis along the lines suggested by Krifka and Verkuyl to assign the appropriate aspectual category to predicates like 'swimAMile', 'playTheMinuteWaltz', etc which we will not analyse further. We will likewise ignore the effect of subjects 
on aspectual category.

\begin{tabular}{|c|c|c|}
\hline 1. $\mathrm{S}$ & $\rightarrow \mathrm{NP} \mathrm{VP}$ & $\lambda$ e. $[\mathrm{VP}(\mathrm{e})](\mathrm{NP})$ \\
\hline 2. NP & $\rightarrow$ Joe, Bill, ... & joe, bill (of type individual) \\
\hline & $\rightarrow 30$ secs, two weeks, ... & 30secs, twoWeeks (of type amount) \\
\hline $\mathrm{VP}$ & $\rightarrow$ sneeze, ... & $\lambda \mathrm{e}_{p t} \lambda \mathrm{x} . \operatorname{sneeze}(\mathrm{e}, \mathrm{x})$ \\
\hline $\mathrm{VP}$ & $\rightarrow$ swim, $\ldots$ & $\lambda \mathrm{e}_{p r} \lambda \mathrm{x} \cdot \operatorname{swim}(\mathrm{e}, \mathrm{x})$ \\
\hline $\mathrm{VP}$ & $\rightarrow$ win, $\ldots$ & $\lambda \mathrm{e}_{\langle p t, s t\rangle} \lambda \mathrm{x} \cdot \operatorname{win}(\mathrm{e}, \mathrm{x})$ \\
\hline $\mathrm{VP}$ & $\rightarrow$ grow old, $\ldots$ & $\lambda \mathrm{e}_{\langle p r, s t\rangle} \lambda \mathrm{x}$.growOld $(\mathrm{e}, \mathrm{x})$ \\
\hline $\mathrm{VP}$ & $\rightarrow$ be tall, ... & $\lambda \mathrm{e}_{s t} \lambda \mathrm{x} \cdot \mathrm{beTall}(\mathrm{e}, \mathrm{x})$ \\
\hline $\mathrm{VP}$ & $\rightarrow$ swim a mile, $\ldots$ & $\lambda \mathrm{e}_{\langle p r, s t\rangle} \lambda \mathrm{x} . \operatorname{swimAMile}(\mathrm{e}, \mathrm{x})$ \\
\hline $\mathrm{VP}$ & $\rightarrow$ play the MW, ... & $\lambda \mathrm{e}_{p r} \lambda \mathrm{x}$. playMW $(\mathrm{e}, \mathrm{x})$ \\
\hline 4. VP & $\rightarrow$ Aux VP & $\lambda \mathrm{e} \lambda \mathrm{x} \cdot[\operatorname{Aux}(\operatorname{coerce}(\mathrm{VP}))](\mathrm{e}, \mathrm{x})$ \\
\hline 5. VP & $\rightarrow \mathrm{VP} \mathrm{PP}$ & $\lambda \mathrm{e} \lambda \mathrm{x} \cdot[\mathrm{PP}(\operatorname{coerce}(\mathrm{VP}))](\mathrm{e}, \mathrm{x})$ \\
\hline Aux & $\rightarrow$ have, be & perf, prog \\
\hline 7. $\mathrm{PP}$ & $\rightarrow \mathrm{P} \mathrm{NP}$ & $\mathrm{P}(\mathrm{NP})$ \\
\hline 8. $\mathrm{P}$ & $\rightarrow$ in, for & $\lambda \mathrm{x} \lambda \mathrm{Q} \cdot \mathrm{P}(\mathrm{x}, \mathrm{Q}))$ etc. \\
\hline
\end{tabular}

The functor 'coerce' is a 'quasi-logical form' construct which can be implemented in various ways. As in Alshawi and Crouch (1992) it could be interpreted as a metavariable which could be instantiated during contextual resolution to the appropriate coercion function (or combination of them). Alternatively it could be given a contextually dependent interpretation via 'conditional equivalences' as in Pulman (1994; 1997).

In our limited fragment we will dispense with these subtleties and assume that 'coerce' can be interpreted as follows, where we will assume that type constraints and non-linguistic factors such as plausibility will determine which interpretation is chosen in a particular instance:

coerce $(\mathrm{VP})=\mathrm{VP}$, or $\mathrm{X}(\mathrm{VP})$, or $\mathrm{X}(\operatorname{coerce}(\mathrm{VP}))$, where $\mathrm{X}$ is 'iterate', 'stretch' etc.

Now we can proceed to some examples. In the examples, eventuality variables are e, f, g; individual variables are $\mathrm{x}, \mathrm{y}, \mathrm{z}$. Note that in discussing the various interpretations provided by the fragment we will make the discussion less cumbersome by referring to the types and denotations of predicates as 'processes', 'states' and the like, although strictly speaking these should be 'functions from processes (or states) to functions from individuals to ... truth values', or 'sets of tuples whose first members are processes or states', respectively. In similar vein we shall talk of the types of the various coercion operators as being ' $\operatorname{prog}_{p r \rightarrow s t}$ ', or 'iterate it $\rightarrow p r$ ', etc.

To determine the interpretation of a sentence like:

49 Joe is sneezing 
the derivation proceeds as follows:

$$
\begin{aligned}
\text { sneeze } & =\lambda \mathrm{e}_{p t} \lambda \mathrm{x} \cdot \operatorname{sneeze}(\mathrm{e}, \mathrm{x}) \\
\text { is sneezing } & =\lambda \mathrm{f} \lambda \mathrm{y} \cdot\left[\operatorname{prog}\left(\operatorname{coerce}\left(\lambda \mathrm{e}_{p t} \lambda \mathrm{x} \cdot \operatorname{sneeze}(\mathrm{e}, \mathrm{x})\right)\right)\right](\mathrm{f}, \mathrm{y}) \\
\text { Joe is sneezing } & =\lambda \mathrm{g} \cdot\left[\left[\lambda \mathrm{f} \lambda \mathrm{y} \cdot\left[\operatorname{prog}\left(\operatorname{coerce}\left(\lambda \mathrm{e}_{p t} \lambda \mathrm{x} \cdot \operatorname{sneeze}(\mathrm{e}, \mathrm{x})\right)\right)\right](\mathrm{f}, \mathrm{y})\right](\mathrm{g})\right](\mathrm{joe}) \\
& =\lambda \mathrm{g}_{s t} \cdot\left[\operatorname{prog}_{p r \rightarrow s t}\left(\operatorname{coerce}_{p t \rightarrow p r}\left(\lambda \mathrm{e}_{p t} \lambda \mathrm{x} \cdot \operatorname{sneeze}(\mathrm{e}, \mathrm{x})\right)\right)\right](\mathrm{g}, \mathrm{joe})
\end{aligned}
$$

First we will assume that 'coerce' is interpreted as 'iterate ${ }_{p t \rightarrow p r}$ ', the most plausible interpretation in the absence of any special context, and a choice that is consistent with the type requirements imposed by 'prog'.

Clause I above tells us that the interpretation of ' $\operatorname{prog}(\mathrm{P})$ ' is a set of tuples whose first members are states which temporally include (or are equivalent to) the process that figures in the interpretation of $\mathrm{P}$. In this case, that process is supplied by the 'iterate (VP)' term, and is constrained by clause $\mathrm{C}$ to temporally include more than one point event in the denotation of the VP 'sneeze', by its definition. Thus, given some assumptions about the interaction of this mechanism with time reference, we will be able to deduce that on this reading, if Joe is sneezing, then Joe has sneezed at least once before the time of utterance.

The only plausible alternative interpretation requires 'coerce' to be interpreted as 'stretch ${ }_{p t \rightarrow p r}$ '. The process that is input to 'prog' is then required by clause D to be temporally equivalent to a point in the denotation of 'sneeze'. Since points are by definition seen as having no internal structure, the model does not support the inference from 'Joe is sneezing' to 'Joe has sneezed' on this interpretation, correctly.

A slightly more complex example is:

50 Joe sneezed for an hour

$$
\begin{aligned}
\text { sneezed } & =\lambda \mathrm{e}_{p t} \lambda \mathrm{x} \cdot \operatorname{sneeze}(\mathrm{e}, \mathrm{x}) \\
\text { for an hour } & =[\lambda \mathrm{x} \lambda \mathrm{Q} \cdot \operatorname{for}(\mathrm{x}, \mathrm{Q}))](\operatorname{anHour}) \\
& =\lambda \mathrm{Q} \cdot \operatorname{for}(\operatorname{anHour}, \mathrm{Q}) \\
\text { sneezed } \mathrm{f} \mathrm{a} \mathrm{h} & =\lambda \mathrm{f} \lambda \mathrm{y} \cdot\left[[\lambda \mathrm{Q} \cdot \operatorname{for}(\operatorname{anHour}, \mathrm{Q})]\left(\operatorname{coerce}\left(\lambda \mathrm{e}_{p t} \lambda \mathrm{x} \cdot \operatorname{sneeze}(\mathrm{e}, \mathrm{x})\right)\right)\right](\mathrm{f}, \mathrm{y}) \\
& =\lambda \mathrm{f} \lambda \mathrm{y} \cdot\left[\operatorname { f o r } \left(\operatorname{anHour},\left(\operatorname{coerce}\left(\lambda \mathrm{e}_{p t} \lambda \mathrm{x} \cdot \operatorname{sneeze}(\mathrm{e}, \mathrm{x})\right)\right](\mathrm{f}, \mathrm{y})\right.\right. \\
\text { Joe s f a } \mathrm{h} & =\lambda \mathrm{g} \cdot\left[\lambda \mathrm{f} \lambda \mathrm{y} \cdot\left[\operatorname{for}\left(\operatorname{anHour},\left(\operatorname{coerce}\left(\lambda \mathrm{e}_{p t} \lambda \mathrm{x} \cdot \operatorname{sneeze}(\mathrm{e}, \mathrm{x})\right)\right](\mathrm{f}, \mathrm{y})\right](\mathrm{g})\right]\right](\mathrm{joe}) \\
& =\lambda \mathrm{g}_{p r \rightarrow s t} \cdot\left[\operatorname { f o r } \left(\operatorname{anHour},\left(\operatorname{coerce}_{p t \rightarrow p r}\left(\lambda \mathrm{e}_{p t} \lambda \mathrm{x} \cdot \operatorname{sneeze}(\mathrm{e}, \mathrm{x})\right)\right](\mathrm{g}, \mathrm{joe})\right.\right.
\end{aligned}
$$

The most plausible choice for the interpretation of the 'coerce' functor is as before, giving us an eventuality with analogous internal structure. The truth conditions for 'for' will tell us that the duration of the process event it applies to is 'an hour'.

Finally, a much more complex example:

51 Joe played the MW in less than 60secs for an hour 


$$
\begin{aligned}
& \text { played the Minute Waltz }=\lambda \mathrm{e}_{p r} \mathrm{x} \cdot \operatorname{playMW}(\mathrm{e}, \mathrm{x}) \\
& \text { in less than } 60 \text { secs }=\lambda \mathrm{Q} \cdot \operatorname{in}(\mathrm{lt} 60, \mathrm{Q}) \\
& \text { playMW in } 1 \mathrm{t} 60=\lambda \mathrm{fy} \cdot\left[\operatorname{in}\left(\mathrm{lt} 60,\left(\operatorname{coerce}\left(\lambda \mathrm{e}_{p r} \mathrm{x} \cdot \operatorname{playMW}(\mathrm{e}, \mathrm{x})\right)\right)\right](\mathrm{f}, \mathrm{y})\right. \\
& =\mathrm{VP} 1 \\
& \text { for an hour }=\lambda \text { R.for }(\text { anHour }, \mathrm{R}) \\
& \text { playMW in lt60 for1hr }=\lambda \mathrm{gz} .[\text { for }(\operatorname{anHour}, \operatorname{coerce}(\mathrm{VP} 1))](\mathrm{g}, \mathrm{z})
\end{aligned}
$$

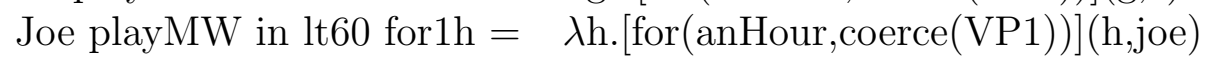

$$
\begin{aligned}
& \left.\lambda \text { h. }\left[\text { for }\left(\operatorname{anHour}, \operatorname{coerce}_{1}\left(\lambda f y \text {. [in(lt60, } \operatorname{coerce}_{2}\left(\lambda \mathrm{e}_{p r} \mathrm{x} \text {.playMW(e,x)) }\right)\right](\mathrm{f}, \mathrm{y})\right)\right)\right](\mathrm{h}, \text { joe })
\end{aligned}
$$

Given that the type of 'in' is ' $\mathrm{in}_{p r, s t \rightarrow p t, s t}$ ' a plausible candidate for 'coerce 2 ' would be 'add-cstate ${ }_{p r \rightarrow p r, s t}$ '. Likewise, given that 'for' has, in this case, type 'for ${ }_{p r \rightarrow p r, s t}$ ', then 'coerce,' can be interpreted as the composition of 'iterate' and 'bundle':

$$
\lambda \text { P.terate }_{p t \rightarrow p r}\left(\text { bundle }_{\alpha \rightarrow p t}(\mathrm{P})\right)
$$

The final interpretation of the sentence will describe the state resulting from an hour long process consisting of repetitions of rapid performances of the Minute Waltz.

Clearly, there is a lot more detailed work to be done before we have a completely satisfactory semantic account, even of these few sentences. We need to link their aspectual properties with temporal reference and other relevant components of meaning. However, the basic contribution of the aspectual coercions to the meaning of these sentences seems to be faithfully captured on the current theory, and there does not seem any reason in principle why such an account cannot be completed in the relevant respects.

\section{Preferences}

An important aspect of the interpretation of sentences like these is that some interpretations are much harder to obtain than others. This is not just a question of how many coercions are required to make the sentence plausible, for some coercions seem to be relatively easy, others not so. For computational purposes it is important that any theory of aspectual coercion should show how to provide some preference measure over the set of interpretations that can be assigned to a sentence. If this is not achieved, then we will be in the position of, for example, many linguistic theories of quantifier scope. Such theories can generate a huge number of interpretations for a sentence, but they leave the computational linguist no better off than before. It is no advance in computational terms to be presented with a set of ambiguities and no way of choosing between them. 
Although, as with any contextual reasoning problem, it will be possible in the limit to find examples which depend on the most arcane piece of specialist knowledge, my feeling is that the most central cases can be accounted for in terms of our knowledge about typical temporal duration of different kinds of event. So we know that the most plausible interpretation of:

52 Joe sneezed for 5 minutes

is an iterative one, because we know that sneezes typically last only a second or so. Likewise, we know that the most plausible interpretation of:

53 Joe was building his house for a year

is that on which the process rather than the consequent state lasts for a year, whereas in:

54 Joe was hiring a car for a week

it is the consequent state that is for a week, and not the hiring itself.

If we can have access to that knowledge about typical durations (a big 'if') then it would be possible to compute a 'cost' for every aspectual combination, by comparing the degree of divergence from the baseline required for the interpretation to be true. The costs of several coercions might well be less than for a single one if the divergence from typical temporal duration was greater in its case.

\section{Address for Correspondence}

SRI International Cambridge Computer Science Research Centre, Suite 23, Millers Yard, Mill Lane, Cambridge CB2 1RQ, UK.

Email:ssp@cam.sri.com

WWW: http://www.cl.cam.ac.uk/users/sgp/

\section{Acknowledgements}

This paper is a revised and expanded version of Chapter 11 of Cooper et al. 1996. The work was originally supported by the FraCaS project, funded by the European Commission, LRE 62-051. I am grateful to the other members of the project for their comments. Versions of the paper have also been read to a seminar at the Dept. of Computational Linguistics, Copenhagen Business School; to the Computer Science departments of Bilkent University, and the Middle Eastern Technical University, Ankara, Turkey; and the Philological Society, London. I am grateful to the audiences on these occasions for their comments. Thanks are due 
to Marc Moens and Mark Steedman for answering questions about their approach to aspectual coercion, and to the latter for supplying a draft of Steedman 1996; to Annabel Cormack, Nancy Chang and especially James Thomas for some useful examples and discussion, and for pointing out some errors in an earlier version; and to Kemal Oflazer for supplying the Turkish examples.

\section{References}

Abadi, Martin and Cardelli, Luca and Pierce, Benjamin and Plotkin, Gordon 1991, Dynamic Typing in a Statically Typed Language, ACM Transactions on Programming Languages and Systems, 13/2, 237-268.

Alshawi, Hiyan 1990, Resolving Quasi-Logical Forms, Computational Linguistics, $16 / 3,133-144$.

Alshawi, Hiyan and Crouch, Richard 1992 Monotonic Semantic Interpretation, in Proceedings 30th Annual Meeting of the Association for Computational Linguistics, 32-38.

Cardelli, Luca and Wegner, Peter 1985 On understanding types, data abstraction, and polymorphism, Computing Surveys 17(4), 471-522.

Cooper, Robin and Crouch, R., van Eijck, J., Fox, C., van Genabith, J., Jaspars, J., Kamp, H., Milward, D., Pinkal, M., Poesio, M., and Pulman, S. 1996 Building the Framework, Deliverable D15, FraCaS project. Available from HCRC, University of Edinburgh, or at http://www.cogsci.ed.ac.uk/ fracas

Bach, Emmon 1981, On Time, Tense, and Aspect: an Essay in English Metaphysics, in P. Cole (ed) Radical Pragmatics, Academic Press, New York: 62-81.

Dowty, David 1979, Word Meaning and Montague Grammar, D. Reidel Publishing Co; Dordrecht, Holland

Hitzeman, Janet 1994 A Reichenbachian account of the interaction of present perfect with temporal adverbials, in 'Computational Discourse Processing' ed. J. Dorrepal, papers from LRE project 'Towards a declarative theory of discourse', Utrech University.

Hitzeman, Janet 1996 Semantic Partition and the Ambiguity of Sentences containing Temporal Adverbials, HCRC Technical Report, Edinburgh.

Hobbs, Jerry and Shieber, Stuart 1987 An Algorithm for generating Quantifier Scopings, Computational Linguistics, 13, 47-63.

Jackendoff, Ray 1991, Parts and Boundaries, in 'Lexical and Conceptual Semantics' ed. B. Levin and S. Pinker, Basil Blackwell, Oxford, 9-45. 
Kamp, Hans and Reyle, Uwe 1993 From Discourse to Logic, Kluwer Academic Publishers, Dordrecht.

Krifka, Manfred 1987, Nominal reference and Temporal Constitution, in Proceedings of the 6th Amsterdam Colloquium: University of Amsterdam, 153-174.

Krifka, Manfred 1991. 4000 ships passed through the lock, Linguistics and Philosophy, Vol 13, 487-520.

Moens, Marc and Steedman, Mark 1988 Temporal Ontology and Temporal Reference, Computational Linguistics, 14: 15-28.

Mourelatos, Alexander 1978, Events, Processes, and States, Linguistics and Philosophy, 1, 199-220.

Pulman, Stephen G. 1977 Syntax and Logical Form in the Analysis of Modals, Ph.D. Thesis, University of Essex Linguistics Department.

Pulman, Stephen G. 1994, A Computational Theory of Context Dependence, in Proceedings: International Workshop on Computational Semantics, ed. H. Bunt, R. Muskens, and G. Rentier, Institute for Language Technology, Tilburg University, The Netherlands, 161-170.

Pulman, Stephen G. 1997, Higher Order Unification and the Interpretation of Focus, Linguistics and Philosophy, 20, 73-115.

Pustejovsky, James 1991 The Syntax of Event Structure, Cognition, 41/1-3. This issue is reprinted as 'Lexical and Conceptual Semantics' ed. B. Levin and S. Pinker, Basil Blackwell, Oxford.

Pustejovsky, James and Bouillon, Pierrette 1996 Aspectual Coercion and Logical Polysemy, in Lexical Semantics: The Problem of Polysemy, ed. J. Pustejovsky and B. Boguraev, Oxford: Clarendon Press, pp 133-162.

Smith, Carlota S. 1991 The Parameter of Aspect, Studies in Linguistics and Philosophy, Vol 43, Dordrecht: Kluwer Academic Publishers.

Steedman, Mark 1996 Temporality. In J. van Benthem and A. ter Meulen, (eds.), Handbook of Logic and Language, Elsevier North Holland, 1996, 895-935.

Stoy, Joseph E. 1977 Denotational Semantics: The Scott-Strachey Approach to Programming Language Theory, MIT Press.

Vendler, Zeno 1967 Linguistics in Philosophy, Cornell University Press, Ithaca, NY.

Verkuyl, Henk 1972 On the Compositional Nature of the Aspects, Dordrecht: Reidel.

Verkuyl, Henk 1989, Aspectual Classes and Aspectual Composition, Linguistics and Philosophy, 12, 39-94. 
Verkuyl, Henk 1993, A Theory of Aspectuality, Cambridge Studies in Linguistics, 64: Cambridge University Press.

Vlach, Frank 1981, The Semantics of the Progressive, in P J Tedeschi and A Zaenen (eds) Syntax and Semantics 14: Tense and Aspect, Academic Press, New York, 271-292. 